\title{
Determination of Ca3(PO4)2 in Bone China by Microwave Digestion-ICP-AES
}

\author{
Zheng-gen Huang ${ }^{1,2^{*}}$, He-ying $\mathrm{Yi}^{1}$, Tao Wang ${ }^{2,}$ Lian-ying $\mathrm{An}^{1,2}$, Xiao-bin Zhao ${ }^{1}$ \\ ${ }^{1}$ National Quality Supervision and Inspection Test Center of Architecture Ceramic, Leshan 614000; \\ ${ }^{2}$ College of Materials and Chemistry \& Chemical Engineering, Chengdu University of Technology, Chengdu 610059.
}

\begin{abstract}
The establishment of a microwave digestion method with the advantages of simple operation and complete digestion to process samples has shown that, high sensitivity, wide linear dynamic range, good precision, fast analysis speed and many other advantages of ICP-AES technology for rapid determination of tricalcium phosphate in bone china. Through the use of different $\mathrm{P} 2 \mathrm{O} 5$ content of phosphate rock and kaolin national standard material configuration standard working solution for matrix matching to eliminate matrix interference, the microwave digestion sample processing condition selection, coexisting ion interference, method precision, accuracy, and detection limit tests were carried out. The results showed that the detection limit of the newly established method for tricalcium phosphate is $0.011 \mathrm{mg}$.L-1; the HCl-HNO3-HF-H2O2 mixed acid decomposition system dissolves the best samples; the interference of the test results through the matrix matching coexisting ion pair is small; The relative standard deviation (RSD) is $1.08 \% \sim 4.64 \%$, and the recovery rate of standard addition is $92.4 \% \sim 107.9 \%$. The established method has high accuracy and precision; the bone china samples are analyzed and compared with the conventional digestion national standard method The $\mathrm{t}$ test method is used to prove that the two methods are not significantly different from the test results.
\end{abstract}

\section{Introduction}

Bone chinaware ${ }^{[1-4]}$ is recognized as the world's most high-end daily-use porcelain. It is made by adding herbivore bone meal as raw material to china clay and firing it in a phosphate system using calcium phosphate as a solvent. Under the illumination of light, it is crystal clear, white and translucent, and the color becomes the unique natural milky white of natural bone meal. The characteristics of bone china are light texture, compact and hard, not easy to wear and tear, high whiteness, good transparency, soft gloss, excellent decorative effect, and particularly pleasant sound. Bone china has always been the best among ceramics since its inception for 300 years. It is a special-purpose porcelain designated by the British royal family and has become the leading consumer of high-end porcelain in China. As an important quantitative analysis index for bone china, the content of tricalcium phosphate is of great significance for the identification of bone chinaware ${ }^{[5]}$. GB/T13522-2008 "Bone China"[6] stipulates that the content of tricalcium phosphate in the product must be greater than $36 \%$. In order to reduce production costs, some manufacturers often use phosphoric acid ore instead of expensive animal ashes. Although this method can introduce a certain amount of calcium phosphate, its crystal structure and the structure of the calcium phosphate in the ashes are different, and the chemical stability in the porcelain-making process is very poor. Therefore, the rapid determination of the content of tricalcium phosphate is of great significance for identifying whether it is bone chinaware and for purifying some propaganda in the industry, and to provide technical advice for the scientific and standardized production of enterprises.

The traditional determination of tricalcium phosphate content in bone chinaware uses phosphoaluminate gravimetric method ${ }^{[7]}$ to determine the content of phosphorus pentoxide and then convert its content. The sample preparation process is complicated, a large amount of acid waste liquid is generated, decomposition is difficult, and the measurement is complicated. The purpose of rapid detection cannot be achieved; in addition, there is the XRF method ${ }^{[8]}$, which is fast but expensive in equipment, limited in popularity and complicated in standard preparation. Microwave digestion and sample dissolution technology ${ }^{[9-11]}$ has the advantages of high efficiency, fast speed, simple operation, safety and reliability, and greatly improves the digestion speed. It has been widely used in geology, environment, metallurgy, biology, food, etc. ${ }^{[9-11]}$ In the industry, reports on the direct use of microwave digestion of bone china to determine the content of tricalcium phosphate are relatively rare. ICP$\mathrm{AES}^{[12-14]}$ technology has high sensitivity, wide linear dynamic range, good precision and fast analysis speed. In this paper, bone china samples were quickly processed by microwave digestion, and matrix interference was eliminated by using standard materials as a standard curve. Coexisting ion interference, method precision, accuracy and detection limit were tested to establish ICP-AES for

\footnotetext{
*Corresponding author's e-mail: 1szjs2102660@aliyun.com
} 
the determination of triphosphate in bone china. The method of calcium content improves work efficiency.

\section{Materials and Methods}

\subsection{Main reagents and instruments}

The analytically pure has included that Argon gas (99.99\%)、 hydrofluoric acid 、 concentrated sulfuric acid 、 concentrated hydrochloric acid, perchloric acid and concentrated nitric acid. The national standard materials have included phosphate rock (GBW07210, GBW07211, GBW07212).The national standard materials have included kaolin (GBW03122) and Deionized water
$(>18.2 \mathrm{M} \Omega . \mathrm{cm})$.

High temperature resistance furnace (China Building Materials Inspection and Certification Group (Shaanxi) Co., Ltd. SX2-4-10), low temperature electric heating plate (Beijing Zhongxing Weiye Instrument Co., Ltd. SKML-1.5-4), analytical balance (Mettler-Toledo ME104E), Sealed laboratory sample preparation crusher (China Building Materials Inspection and Certification Group (Shaanxi) Co., Ltd. YHGJ-1), fast grinder (China Building Materials Inspection and Certification Group (Shaanxi) Co., Ltd. KNM-1); microwave digestion apparatus (Shanghai New Instrument Microwave Chemical Technology Co., Ltd. MDS-6); ICP-AES (Thermo ICAP-6000), other working parameters of the instrument are shown in Table 1.

Table 1 ICAP-6000 instrument parameters

\begin{tabular}{cc|cc}
\hline Working parameters & Set conditions & Working parameters & Set conditions \\
\hline RF & $1150 \mathrm{~W}$ & Integration time & Short wave $10 \mathrm{~s}$, long wave $5 \mathrm{~s}$ \\
Ar flow & $0.5 \mathrm{~L} / \mathrm{min}$ & Light room temperature & $(38 \pm 0.1)^{\circ} \mathrm{C}$ \\
vertical height & $15 \mathrm{~mm}$ & Pump flushing time & $25 \mathrm{~s}$ \\
pump speed & $50 \mathrm{r} / \mathrm{min}$ & Nebulizer pressure & $0.2 \mathrm{MPa}$ \\
\hline
\end{tabular}

\subsection{Sample preparation}

The bone china samples were cut with a polishing mill, polished to remove the glaze layer on the surface, crushed and passed through a $125 \mu \mathrm{m}$ sample sieve, dried at $105^{\circ} \mathrm{C} \pm 5^{\circ} \mathrm{C}$ with constant weight and placed in a desiccator for use.

Accurately weigh $0.1 \mathrm{~g}$ (accurate to $0.0001 \mathrm{~g}$ ) sample into a polytetrafluoroethylene digestion tank, and add a few drops of water to wet the sample. Add $6.0 \mathrm{~mL}$
$\mathrm{HCl}+2 \mathrm{~mL} \mathrm{HNO}_{3}+2 \mathrm{~mL} \mathrm{HF}$ for the first group, $6.0 \mathrm{~mL}$ $\mathrm{HCl}+2 \mathrm{~mL} \mathrm{HNO}_{3}+2 \mathrm{~mL} \mathrm{HF}+1 \mathrm{~mL} \mathrm{H}_{2} \mathrm{O}_{2}$ for the second group, $8 \mathrm{~mL} \mathrm{HNO}_{3}$ for the third group, $6 \mathrm{~mL} \mathrm{HCl}+2 \mathrm{~mL}$ $\mathrm{HNO}_{3}$ for the fourth group, and $6 \mathrm{~mL}$ for the fifth group After soaking in $\mathrm{HNO}_{3}-2 \mathrm{~mL} \mathrm{H}_{2} \mathrm{SO}_{4}$, after the reaction is stable and the foam is basically eliminated, tighten the lid, put it into the microwave digestion apparatus, and perform digestion under the conditions in Table 2. After the digestion is completed, drive the acid at $140^{\circ} \mathrm{C}$ in the electric heating plate until the smoke is exhausted, add water to a volumetric flask and add a blank test at the same time.

Table 2 Conditions of microwave digestion

\begin{tabular}{ccccc}
\hline step & MPa & $\mathrm{t} / \mathrm{min}$ & $\mathrm{W}$ & $\min$ \\
\hline 1 & 0.3 & 3 & 200 & 3 \\
2 & 0.6 & 3 & 400 & 2 \\
3 & 0.9 & 3 & 800 & 3 \\
4 & 1.2 & 3 & 1000 & 3 \\
5 & 1.5 & 4 & 600 & 4 \\
6 & 1.8 & 2 & 400 & 2 \\
\hline
\end{tabular}

\subsection{Standard working solution preparation}

Bone china is made of mineral materials such as quartz, kaolin, feldspar, and animal bone ashes after high temperature sintering. Its matrix composition is relatively complex, and the content of elements in it spans a wide range, from trace to constant. The test has not eliminate the interference of the substrate. The paper uses the matrix matching method to eliminate matrix interference to improve the accuracy of the test results processing. Weigh the national standard materials GBW03122 (kaolin, wP2O5\%=0.21\%), GBW07212 (phosphate rock, wP2O5\% $=6.06 \%$ ), GBW07211 (phosphate rock, wP2O5\%=20.86\%), GBW07210 (Phosphate rock, $\mathrm{wP} 2 \mathrm{O} 5 \%=36.89 \%$ ). After sample processing is carried out according to the microwave digestion and sample dissolution method in the previous 1.2 sample pretreatment method, prepare the standard working solution according to the requirements of Table 3 and save it for later use. 
Table 3 Standard working solution preparation

\begin{tabular}{cccccc}
\hline $\begin{array}{c}\text { Standard working } \\
\text { solution number }\end{array}$ & $\begin{array}{c}\text { Reference } \\
\text { material name }\end{array}$ & $\mathrm{m} / \mathrm{g}$ & $\mathrm{V} / \mathrm{mL}$ & $\rho$ P205 $/{\mathrm{mg} . \mathrm{L}^{-1}}^{-1}$ & $\rho_{\text {Ca3(PO4) } / \mathrm{mg} . \mathrm{L}^{-1}}$ \\
\hline 0 & $/$ & 0.1 & 250 & 0 & 0 \\
1 & GBW03122 & 0.1 & 250 & 0.84 & 1.84 \\
2 & GBW07212 & 0.1 & 250 & 24.24 & 52.97 \\
3 & GBW07211 & 0.1 & 250 & 83.44 & 182.34 \\
4 & GBW07210 & 0.1 & 250 & 147.56 & 322.46 \\
\hline
\end{tabular}

\section{Results and discussion}

\subsection{The effect of coexisting ions in the solution and the elimination of matrix interference}

In the preparation of the standard working solution, the phosphate rock and kaolin national standard materials similar to the test matrix are used for matrix matching; the interference between elements can be selected by the appropriate analysis spectrum to avoid interference, and the best can be checked through the application of ICPAES software. Optimal linear range of spectral lines to ensure the best linear fit. Conducted interference experiments on common coexisting ions in bone china leaching solution, adding $100 \mu \mathrm{g} / \mathrm{mL} \mathrm{K}^{+} 、 \mathrm{Na}^{+} 、 \mathrm{Fe}^{3+} 、 \mathrm{Cu}^{2+}$ 、 $\mathrm{Ti}^{4+} 、 \mathrm{Ca}^{2+}$ and $\mathrm{Mg}^{2+}$ to the leaching solution of 5 different

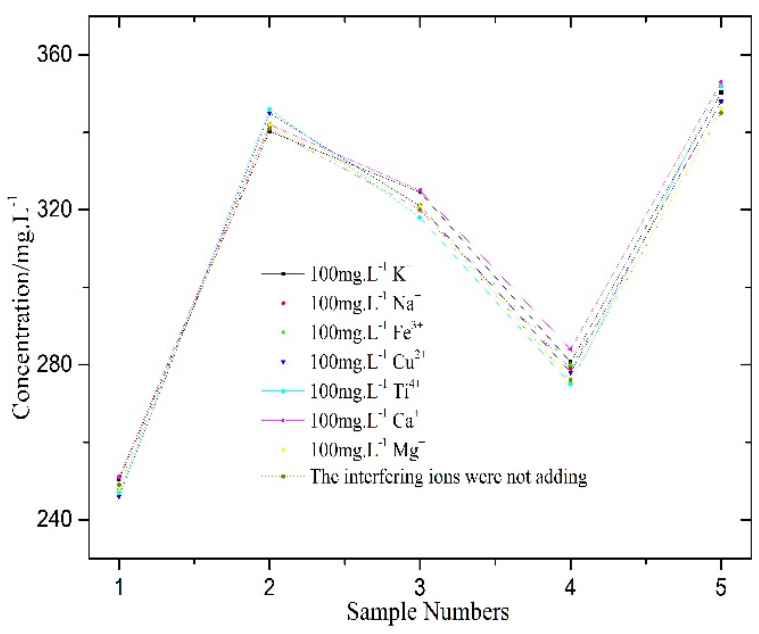

Figure 1 The influence of interfering ions on test results

\subsection{The detection limit}

Prepare a blank solution according to the aforementioned 1.2 sample processing method and repeat the determination 11 times. According to the analysis steps bone china samples to observe and treat Measure the interference of the target substance $\mathrm{Ca}_{3}\left(\mathrm{PO}_{4}\right)_{2}$, and the results are shown in Figure 1. The selection results show that the coexisting ions have basically no interference after matrix matching.

\subsection{Standard curve drawing}

The emission intensity of the standard series of solutions was measured according to the instrument parameter conditions optimized by ICP-AES, and the selected analysis line was $213.618 \mathrm{~nm}$. Use the emission intensity signal response value Cts. $\mathrm{S}^{-1}$ as the ordinate and the standard working solution concentration $/ \mathrm{mg} . \mathrm{L}^{-1}$ as the abscissa to draw the working curve. The results are shown in Figure 2 below. The correlation coefficient of the linear regression equation of $\mathrm{Ca}_{3}\left(\mathrm{PO}_{4}\right)_{2}$ is 0.9998 , and the linear fit is excellent.

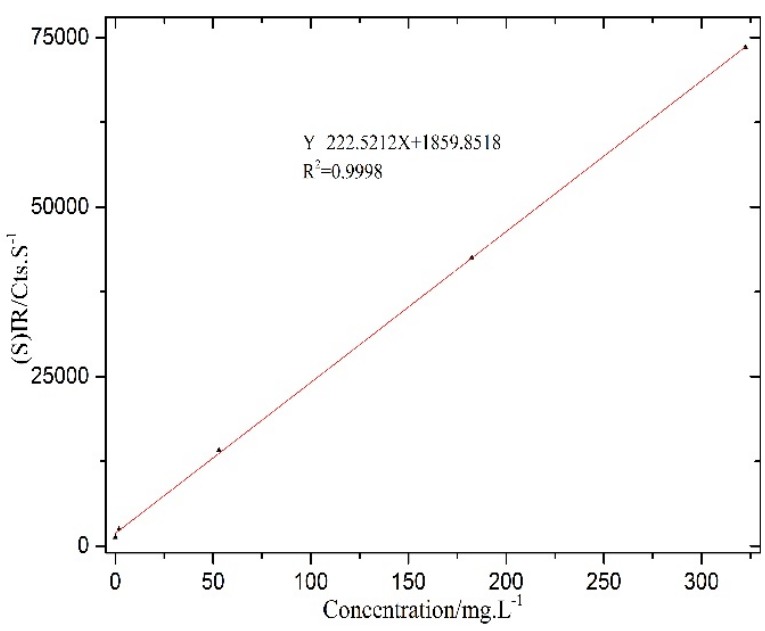

Figure 2 Standard curve of $\mathrm{Ca}_{3}\left(\mathrm{PO}_{4}\right)_{2}$

and test conditions of this method, the detection limit of the method is calculated by 3 times the standard deviation (SD), and the detection limit is $0.011 \mathrm{mg} . \mathrm{L}^{-1}$. The detection limit of the target content method completely meets the requirements for the determination of tricalcium phosphate in bone china. 


\subsection{Selection of ore dissolution}

In view of the characteristics of the bone china samples belonging to the silicate system ${ }^{[15]}$, this paper selects 5 types of digestion systems including $\mathrm{HCl}-\mathrm{HNO}_{3}-\mathrm{HF}$ 、 $\mathrm{HCl}$ $\mathrm{HNO}_{3}-\mathrm{HF}-\mathrm{H}_{2} \mathrm{O}_{2} 、 \mathrm{HNO}_{3} 、 \mathrm{HNO}_{3}-\mathrm{H}_{2} \mathrm{SO}_{4}$ and aqua regia, according to Table 1- Under 2 conditions, four national standard materials GBW03122 kaolin, GBW07210 phosphate rock, GBW07212 phosphate rock, GBW07212 phosphate rock were subjected to microwave digestion test $(0.1 \mathrm{~g}$ digestion constant volume to $500 \mathrm{~mL})$, and the measurement results are shown in Table 4.

Table 4. The determination of $\mathrm{Ca}_{3}\left(\mathrm{PO}_{4}\right)_{2}$ analytical results from the different conditions microwave digestion

\begin{tabular}{|c|c|c|c|c|}
\hline \multirow[b]{2}{*}{ Digestion system } & \multicolumn{4}{|c|}{$\mathrm{W}_{\mathrm{Ca} 3(\mathrm{PO} 4) 2} /\left(\mathrm{mg} \cdot \mathrm{L}^{-1}\right)$} \\
\hline & $\begin{array}{c}\text { GBW03122 } \\
\text { average value } \\
(\mathrm{n}=4)\end{array}$ & $\begin{array}{c}\text { GBW07210 } \\
\text { average value } \\
(\mathrm{n}=4)\end{array}$ & $\begin{array}{c}\text { GBW07211 } \\
\text { average value } \\
(\mathrm{n}=4)\end{array}$ & $\begin{array}{c}\text { GBW07212 } \\
\text { average value } \\
(\mathrm{n}=4)\end{array}$ \\
\hline $\mathrm{HCl}-\mathrm{HNO}_{3}-\mathrm{HF}$ & 0.86 & 155.89 & 90.12 & 25.68 \\
\hline $\begin{array}{c}\mathrm{HCl}-\mathrm{HNO}_{3}-\mathrm{HF}- \\
\mathrm{H}_{2} \mathrm{O}_{2}\end{array}$ & 0.90 & 159.97 & 90.56 & 26.28 \\
\hline $\mathrm{HNO}_{3}$ & 0.76 & 150.12 & 87.25 & 25.01 \\
\hline $\mathrm{HNO}_{3}-\mathrm{H}_{2} \mathrm{SO}_{4}$ & 0.87 & 153.56 & 90.17 & 25.62 \\
\hline Aqua regia & 0.81 & 151.29 & 88.12 & 25.42 \\
\hline Recommend & 0.92 & 161.23 & 91.17 & 26.48 \\
\hline
\end{tabular}

It can be seen from the table that under the two digestion conditions of $\mathrm{HNO}_{3}$ and aqua regia, the sample still has a small amount of precipitation. Due to the high silicon content in the sample and the incomplete decomposition, the measured value is low; $\mathrm{HNO}_{3}-\mathrm{H}_{2} \mathrm{SO}_{4}$ is also in line with the recommended value of the standard substance. Some deviations may be caused by the high boiling point of $\mathrm{H}_{2} \mathrm{SO}_{4}$ and incomplete sample digestion. If the temperature of the microwave digestion apparatus is set too high and the pressure is too high, it is not advisable from the aspects of instrument damage and experimental safety; $\mathrm{HCl}-\mathrm{HNO}_{3}-\mathrm{HF}-\mathrm{H}_{2} \mathrm{O}_{2}$ decomposes well, and the test result is close to the recommended value of the sample.

\subsection{Standard recovery, accuracy and precision test}

Select 5 bone china samples according to the sample processing method in 1.2, and each sample is processed in three parts, one of which measures the original background value, and the other two are added with an appropriate amount of known tricalcium phosphate according to the gradient before sample processing For quality control samples, perform sample testing, and measure the same sample three times in parallel $(n=3)$, and calculate the corresponding spike recovery and RSD. The results are shown in Table 5. The results of the standard addition recovery test show that the recovery rate of the test samples is between $92.4 \%$ and $107.9 \%$, indicating that the established detection method has good accuracy; the relative standard deviation (RSD) between $1.08 \%$ and $4.64 \%$ indicates the new establishment The detection method has high precision and repeatability.

Table 5 Standard addition recovery and precision test

\begin{tabular}{|c|c|c|c|c|c|c|c|c|c|c|}
\hline \multirow[b]{2}{*}{ Project } & \multirow[b]{2}{*}{ Sample No } & \multicolumn{3}{|c|}{$\mathrm{mg} \cdot \mathrm{L}^{-1}$} & \multirow{2}{*}{$\begin{array}{l}\text { Recover } \\
\text { y rate } \%\end{array}$} & \multirow[b]{2}{*}{ RSD\% } & \multicolumn{2}{|c|}{ mg.L $\mathrm{L}^{-1}$} & \multirow{2}{*}{$\begin{array}{l}\text { Recovery } \\
\text { rate } \%\end{array}$} & \multirow[b]{2}{*}{ RSD $\%$} \\
\hline & & $\begin{array}{c}\text { Background } \\
\text { value }\end{array}$ & Scalar & $\begin{array}{c}\text { measured } \\
\text { value }\end{array}$ & & & Scalar & $\begin{array}{c}\text { measured } \\
\text { value }\end{array}$ & & \\
\hline \multirow{5}{*}{$\mathrm{W}_{\mathrm{Ca} 3(\mathrm{PO} 4) 2}$} & $1^{\#}$ & 240.56 & 52.97 & 295.32 & 103.4 & 2.97 & 105.94 & 350.12 & 103.4 & 3.98 \\
\hline & $2^{\#}$ & 260.56 & 52.97 & 310.03 & 93.4 & 4.12 & 105.94 & 371.67 & 104.9 & 4.64 \\
\hline & $3^{\#}$ & 183.98 & 52.97 & 241.12 & 107.9 & 3.10 & 105.94 & 285.34 & 95.7 & 4.20 \\
\hline & $4^{\#}$ & 212.87 & 52.97 & 261.84 & 92.4 & 1.08 & 105.94 & 310.9 & 92.5 & 3.22 \\
\hline & $5^{\#}$ & 202.68 & 52.97 & 254.17 & 97.2 & 2.87 & 105.94 & 310.24 & 101.5 & 2.91 \\
\hline
\end{tabular}




\subsection{Sample analysis and method comparison}

The established method was used to analyze the content of tricalcium phosphate in different bone china samples, and compared with the conventional national standard method GB/T1871.1-1995, the $t$ test method [17] was used to determine whether the two methods are significantly different. See Table 6.

Table6. Comparison of analytical results of microwave digestion-ICP-AES and traditional digestion method

\begin{tabular}{|c|c|c|c|c|c|}
\hline \multirow{2}{*}{ Sample No } & \multicolumn{2}{|c|}{ ICP-AES W $\mathrm{Ca}_{\text {(PO4)2 }} /(\%)$} & \multicolumn{2}{|c|}{$\mathrm{W}_{\mathrm{Ca} 3(\mathrm{PO} 4) 2} /(\%)$} & \multirow[b]{2}{*}{$\mathrm{t}$} \\
\hline & $\begin{array}{c}\text { average value } \\
(\mathrm{n}=4)\end{array}$ & $\mathrm{RSD} \%$ & $\begin{array}{c}\text { average value } \\
(\mathrm{n}=4)\end{array}$ & RSD $\%$ & \\
\hline 2020STJG001 & 37.76 & 2.58 & 37.90 & 4.12 & 0.99 \\
\hline 2020STJG002 & 38.08 & 0.78 & 37.65 & 3.89 & 1.34 \\
\hline 2020STJG003 & 25.89 & 1.20 & 25.80 & 0.89 & 0.80 \\
\hline 2020STJG004 & 34.89 & 3.24 & 34.26 & 3.98 & 1.80 \\
\hline 2020STJG005 & 40.24 & 2.90 & 39.86 & 4.51 & 1.08 \\
\hline 2020STJG006 & 38.65 & 3.71 & 36.29 & 3.80 & 0.78 \\
\hline 2020STJG007 & 34.32 & 2.29 & 34.08 & 3.72 & 1.67 \\
\hline 2020STJG008 & 35.60 & 3.31 & 35.30 & 1.90 & 1.02 \\
\hline 2020STJG009 & 37.62 & 3.70 & 37.36 & 2.80 & 1.01 \\
\hline 2020STJG010 & 36.80 & 2.80 & 36.46 & 4.43 & 0.98 \\
\hline
\end{tabular}

It can be seen from the table that the relative standard deviation RSD of the two methods of microwave digestion-ICP-AES method and national standard conventional digestion gravimetric method to determine the content of tricalcium phosphate $(\%)$ are $0.78 \% \sim 3.71 \%$ and $0.89 \% \sim 4.51 \%$ respectively. It has good repeatability and precision; the t-test method judges the two sets of data obtained by using two methods for each sample. After calculation, all $\mathrm{t}<\mathrm{t} 0.05,6=2.45^{[16]}$ (95\% confidence , Degree of freedom $\mathrm{f}=6$ ), indicating that there is no significant difference between the newly established microwave digestion-ICP-AES method and the conventional digestion gravimetric method, and the measurement results of the two methods are in good agreement.

\section{Conclusion}

A microwave digestion-ICP-AES method for rapid determination of tricalcium phosphate content in bone china has been established. Compared with traditional inspection methods, it has the advantages of high accuracy, good precision, short time consumption, and no significant difference in test results. It has Identified that the quality of bone china, improve the production technology level of this type of product, and provide a certain technical reference for the formulation and revision of the next method standards.

\section{References}

1. Lan Lan. Treasures of Bone China, Combination of Art and Art[J]. Commodity \& Quality, 2012, 1(33): $82-83$
2. Norazne Nasir, Nor Hayati Saad, Norrul Hafizan Ab Wahab, Bulan Abdullah, Abdul Rahim Mahamad Sahab. Product Performance Analysis of Fine Bone China Using Ceramic Slip Rotary Moulding Process[J]. Applied Mechanics and Materials, 2020, 6046(01): 180-186.

3. Elif Kabakci, Ahmet Capoglu. Microstructural and technological investigation of bone China reformulated with nepheline syenite and quartz addition[J]. International Journal of Applied Ceramic Technology. 2020, 17(3):1128-1140.

4. Salman Siddique, Sandeep Shrivastava, Sandeep Chaudhary. Durability properties of bone china ceramic fine aggregate concrete[J]. Construction and Building Materials, 2018, 173(1): 323-331.

5. Wang Dong, Li Kehong, Bai Yankun. The effect of glaze in bone china on the determination of tricalcium phosphate content $[\mathrm{J}]$. China Packaging Industry, 2013, 1(04): 8-9.

6. GB/T 13522-2008, Bone China[S].

7. GB/T1871.1-1995. Determination of Phosphorus Pentoxide Content in Phosphate Concentrates and Phosphate Rocks-Quinoline Phosphomolybdate Gravimetric Method and Volumetric Method [S].

8. Fang Tao, Wu Yu, Li Wenjie, Yuan Wenzhan, Zhao Shuzhong. X-ray fluorescence spectrometry analysis of the content of tricalcium phosphate in "bone china"[J]. Chinese Ceramics, 2012, 48(01): 46-48+72.

9. Ji Caiye, Liu Yuyan, Wu Dan, et al. Dynamic change in particulate palladium concentrations in a mangrove wetland water environment and its mechanism in Dongzhai Harbor, China. 2020, 82(11): 2503-2512.

10. Zeng Y B, Xu H P, Liu H T, et al. Application of 
artificial neural networks in multifactor optimization of an on-line microwave FIA system for catalytic kinetic determination of Ruthenium ( III)[J]. Talanta, 2001, 54(4): 603- 609.

11. Djingova R, Heidenreich $H$, Kovacheva $P$, et al . On the determination of platinum group elements in environmental materials by Inductively Coupled Plasma Mass Spectrometry and microwave digestion[J]. Anal. Chim. Acta, 2003, 489(2): 245251.

12. Babalola, Sadiat Oyenike, Akinwande, Bolanle Aishat. Determination of minerals by ICP-AES in indigenous vegetables from Southwest Nigeria[J]. Nutrition and Food Science. 2014; 44(03): 249-257.

13. V. A. Fassel. Current and potential applications of inductively coupled plasma (ICP)-atomic emission spectroscopy (AES) in the exploration, mining, and processing of materials [J]. Pure and Applied Chemistry, 2013, 49(10): 1533-1545.

14. Sumida Takashi, Yamashita Minoru, Okazaki Yuka, Kawakita Hirohisa, Fukutomi Takashi. Synthesis of cellulose functionalized with polyallylamine and its application to on-line collection/concentration and determination of phosphate by ICP/AES[J]. Analytical Sciences (Online), 2012, 28(8): 767-772.

15. Dai Jinhui, Ge Zhaoming. Concept of Inorganic Nonmetallic Materials[M]. Harbin: Harbin Institute of Technology Press, 2004.

16. Wuhan University. Analytical Chemistry [M]. Beijing: Higher Education Press, 2006. 